\title{
PELATIHAN PENGGUNAAN BUKU SAKU UNTUK MEMBANGUN MINAT BELAJAR SISWA SMP
}

\author{
Tatik Retno Murniasih ${ }^{1 *}$, Sri Hariyani², Rosita Dwi Ferdiani ${ }^{3}$ \\ ${ }^{1 *}$ Program Studi Pendidikan Matematika, Universitas Kanjuruhan Malang \\ ${ }^{2}$ Program Studi Pendidikan Matematika, Universitas Kanjuruhan Malang \\ ${ }^{3}$ Program Studi Pendidikan Matematika, Universitas Kanjuruhan Malang \\ Corresponding author : \\ E-mail : tretnom@unikama.ac.id
}

Diterima 5 Oktober 2019, Disetujui 18 Oktober 2019

\begin{abstract}
ABSTRAK
Berdasarkan hasil observasi awal didapatkan permasalahan pada SMP Miftahul Ulum Ngembal dan SMP Islam PGRI Tutur yaitu penggunaan buku paket yang kurang efektif bagi siswa serta tidak semua siswa memiliki buku paket. Hal ini menyebabkan pembelajaran materi Sistem Persamaan Linier Dua Variabel tidak berjalan dengan baik sehingga diperlukan media inovatif berupa buku saku. Media buku saku yang ukurannya kecil, efisien untuk dibawa dan harganya juga murah. Pengabdian kepada masyarakat ini mempunyai target membangun minat belajar siswa dalam mempelajari materi Sistem Persamaan Linier Dua Variabel. Metode yang ditawarkan terdiri dari: a) Persiapan berupa tersedianya buku saku serta petunjuk penggunaan oleh pengabdi kepada siswa, dan b) Pelaksanaan berupa penggunaan dan pendampingan media buku saku untuk materi Sistem Persamaan Linier Dua Variabel. Kegiatan pengabdian ini telah memberi banyak manfaat bagi SMP Miftahul Ulum Ngembal dan SMP Islam PGRI Tutur. Berdasarkan tanya jawab pada akhir kegiatan didapatkan minat belajar siswa meningkat dengan adanya media buku saku.
\end{abstract}

Kata kunci: pelatihan, buku saku, minat belajar.

\begin{abstract}
Based on preliminary observations, problems were found in Miftahul Ulum Ngembal Middle School and PGRI Tutur Islamic Middle School, namely the use of textbooks which were less effective for students and not all students had textbooks. This causes the learning of the material of the Two Variable Linear Equation System to not run well so that innovative media in the form of pocket books is needed. Pocket book media that is small in size, efficient to carry and the price is also cheap. Community service has the target of building student interest in learning the material of the Two Variable Linear Equation System. The method offered consists of: a) Preparation in the form of the availability of pocket books and instructions for use by devotees to students, and b) Implementation of the use and assistance of pocket book media for the Linear Equation System for Two Variables. This dedication activity has provided many benefits for Miftahul Ulum Ngembal Middle School and PGRI Tutur Islamic Middle School. Based on questions and answers at the end of the activity it was found that students' interest in learning increased with the presence of a pocket book.
\end{abstract}

Keywords: training, pocket books, interest in learning.

\section{PENDAHULUAN}

Salah satu Sekolah Menengah Pertama di Kabupaten Pasuruan antara lain SMP Miftahul Ulum Ngembal. Sebagian besar siswa di SMP Miftahul Ulum Ngembal dari keluarga peternak dan petani tegal sehingga siswa kurang mendapat dukungan dari keluarga tentang pentingnya pendidikan. Menurut Nurkholis ( 2013) pentingnya pendidikan dapat dilihat dari dua aspek yaitu kognitif dan afektif. Misalnya, siswa yang mempelajari materi tertentu bekan hanya proses berpikir yang terjadi namun ada unsur perasaan seperti minat dan lain-lain. Hal ini menunjukkan pentingnya pendidikan tidak boleh hanya dilihat dari aspek kognitif saja. Bahkan di SMP Miftahul Ulum Ngembal sering terjadi, siswa putus sekolah dikarenakan harus bekerja atau menikah di usia dini.

Sedangkan di SMP Islam PGRI Tutur dalam proses pembelajaran, kurikulum yang digunakan adalah kurikulum KTSP 2006. Buku pelajaran untuk siswa masih sangat kurang. Media untuk pembelajaran juga tidak ada 
disebabkan kurangnya dana sekolah untuk menyediakan media pembelajaran. Siswa hanya menggunakan buku LKS untuk menunjang pembelajaran di kelas.

Pengabdi melakukan observasi awal di SMP Miftahul Ulum Ngembal dan SMP Islam PGRI Tutur. Berdasarkan hasil dialog dengan guru dan kepala sekolah di SMP Miftahul Ulum Ngembal dan SMP Islam PGRI Tutur, didapatkan informasi bahwa pembelajaran matematika khususnya materi Sistem Persamaan Linier 2 Variabel, jarang menggunakan media pembelajaran inovatif. Siswa mempelajari matematika dengan buku paket dan penjelasan guru. Diperlukan media inovatif agar pembelajaran menjadi bermakna (Sukaesih \& Alimah, 2012). Media pembelajaran merupakan salah satu komponen untuk mengajarkan agar pembelajaran di kelas menjadi lebih bermakna.

Pemanfaatan buku paket oleh siswa di SMP Miftahul Ulum Ngembal dan SMP Islam PGRI Tutur masih kurang. Menurut guru di SMP Miftahul Ulum Ngembal dan SMP Islam PGRI Tutur beberapa siswa tidak membawa buku paket pada saat pembelajaran. Kesimpulan hasil wawancara pengabdi dengan beberapa siswa yang tidak membawa buku paket antara lain: buku paket berukuran besar sehingga kurang efektif jika dibawa kemana-mana. Diperlukan media inovatif berupa buku saku guna memberi solusi terhadap masalah siswa di SMP Miftahul Ulum Ngembal dan SMP Islam PGRI Tutur. Menurut (Asyhari \& Silvia, 2016) media buku saku dapat menarik minat siswa dan memberi kemudahan dalam memahami materi tertentu.

\section{METODE PELAKSANAAN}

Metode yang digunakan dalam kegiatan pengabdian dibagi menjadi dua bagian yaitu:

1. Persiapan

Terrsedianya buku saku serta petunjuk penggunaan buku saku oleh pengabdi kepada siswa.

2. Penggunaan dan pendampingan media buku saku untuk materi SPLDV.

Dukungan berupa partisipasi aktif dari sekolah mitra dalam pelaksanaan pengabdian sangat menentukan keberhasilan dan keberlanjutan program. Untuk mendorong partisipasi aktif dari siswa dalam pelaksanaan program, maka dilakukan beberapa hal sebagai berikut:

a. Pembagian buku saku pada masing-masing siswa

Siswa dapat langsung menggunakan buku saku sehingga dapat langsung praktik menggunakan dalam mempelajari materi SPLDV.

b. Pendampingan siswa

Pendampingan terhadap siswa di kelas pada saat penggunaan buku saku. Tanya jawab dan diskusi antara pengabdi dan siswa di kelas akan membantu siswa menemukan solusi dari permasalahan yang dihadapi.

Alur kegiatan pengabdian dapat dilihat pada Gambar 1 berikut.

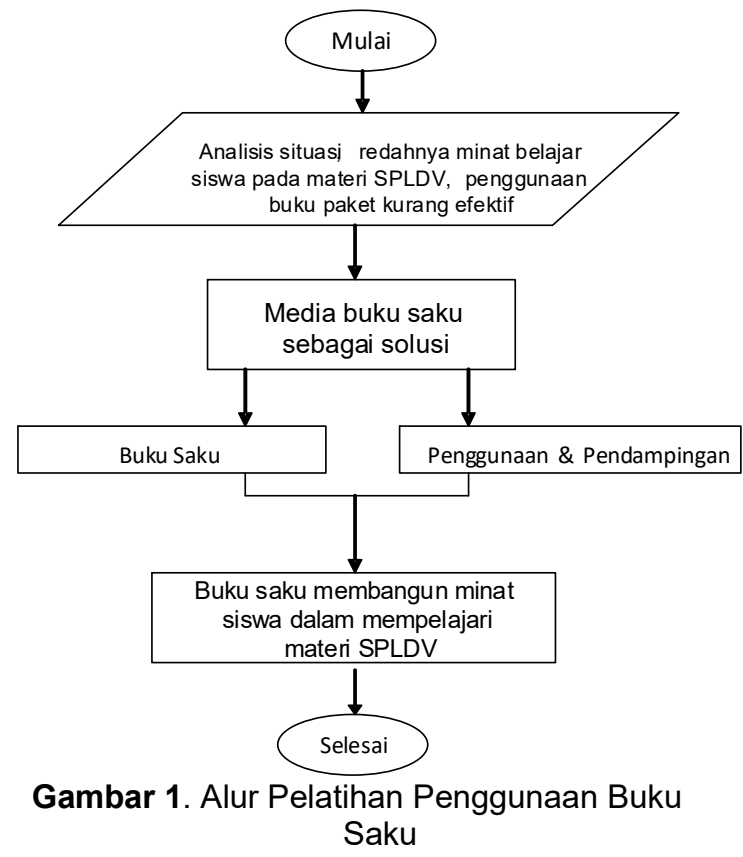

HASIL DAN PEMBAHASAN

Berdasakan analisis situasi didapatkan minat belajar siswa pada materi SPLDV dengan menggunakan buku paket masih rendah. Buku paket yang berukuran besar dan tidak semua siswa memiliki dianggap kurang efektif. Diperlukan media buku saku yang dapat membangun minat belajar siswa pada materi SPLDV.

Kegiatan pengabdian memberikan banyak manfaat bagi SMP Miftahul Ulum Ngembal dan SMP Islam PGRI Tutur. Manfaat yang didapatkan antara lain siswa dapat memanfaatkan buku saku sebagai media pembelajaran inovatif yang selama ini belum pernah didapatkan. Siswa merasakan pengalaman baru belajar menggunakan media buku saku.

Kegiatan pelatihan tentang penggunaan media buku saku materi Sistem Persamaan Linier Dua Variabel dilaksanakan selama 2 kali pertemuan di masing-masing sekolah dan disesuakan dengan jadwal 
sekolah. Kegiatan di sekolah SMP Miftahul Ulum Ngembal dilaksanakan hari Senin sesuai jadwal matematika. Sedangkan kegiatan di SMP Islam PGRI Tutur dilaksanakan hari Rabu.

Kegiatan pada pertemuan pertama dimulai dengan tanya jawab antara pengabdi dan siswa tentang materi Persamaan Linier Dua Variabel. Selanjutnya pengabdi menanyakan pada siswa terkait perbedaan persamaan linier dua variabel dan sistem persamaan linier dua variabel. Setelah kegiatan tanya jawab selesai, pengabdi mengenalkan dan memberi petunjuk penggunaan buku saku materi Sistem Persamaan Linier Dua Variabel. Setelah itu pengabdi membagikan buku saku kepada siswa. Indikator yang ingin dicapai pada kegiatan pertemuan pertama antara lain: a) Dengan menggunakan media buku saku siswa dapat menyebutkan perbedaan PLDV dan SPLDV, dan b) Dengan menggunakan media buku saku siswa dapat mengenal variabel serta koefisien.

Indikator yang ingin dicapai pada kegiatan pertemuan kedua antara lain: a) Dengan menggunakan media buku saku siswa dapat menentukan penyelesaian SPLDV dengan substitusi, eliminasi dan grafik, b) Dengan menggunakan media buku saku siswa dapat membuat model matematika dari masalah sehari-hari yang melibatkan SPLDV, dan c) Dengan menggunakan media buku saku siswa dapat menentukan penyelesaian model matematika terkait SPLDV. Kegiatan pada pertemuan kedua berguna untuk menggali minat siswa dalam mempelajari materi SPLDV dengan menggunakan buku saku. Tampilan media buku saku yang berukuran kecil $10 \times 15$ $\mathrm{cm}$ menyebabkan buku saku bisa disimpan di saku baju sehingga mudah untuk dibawa kemana-mana dan jika siswa lupa dengan materi SPLDV maka siswa bisa langsung membuka buku yang disimpan di saku baju. Kegiatan pengabdian diakhiri dengan latihan soal dan tanya jawab tentang SPLDV. Berdasarkan hasil tanya jawab didapatkan hasil siswa lebih berminat menggunakan media inovatif dalam pembelajaran. Hal ini sesuai dengan pendapat (Ferdiani, Murniasih, \& Suwanti, 2017) yang mengatakan penggunaan media dalam pembelajaran dapat meningkatkan minat siswa.

Beberapa faktor penghambat maupun pendukung kegiatan pengabdian. Faktor pendukung dari kegiatan pelatihan penggunaan media buku saku antara lain:

a. Tim pengabdi diterima dengan baik di SMP Miftahul Ulum Ngembal dan SMP Islam PGRI Tutur. b. Minat siswa yang tinggi dalam menggunakan buku saku sebagai media alternatif dalam pembelajaran.

Sedangkan faktor penghambat dari kegiatan pengabdian yaitu jarak yang lumayan jauh kurang lebih 40 km dari Universitas Kanjuruhan serta kemacetan lalu lintas membuat kegiatan harus dijadwalkan dengan baik.

Keuntungan bagi pengabdi dengan adanya kegiatan ini yaitu dapat mengaplikasikan Tri Dharma Perguruan Tinggi. Sedangkan keuntungan bagi siswa akan menambah wawasan siswa dalam mengenal, memahami, dan mengaplikasikan materi SPLDV dengan menggunakan media buku saku. Minat belajar siswa SMP Miftahul Ulum Ngembal dan SMP Islam PGRI Tutur untuk mempelajari matematika menjadi meningkat. Hal ini terlihat pada akhir kegiatan dilakukan tanya jawab secara umum mengatakan lebih berminat belajar dengan menggunakan buku saku. Siswa yang lebih berminat dalam mempelajari materi mengakibatkan siswa lebih mudah untuk memahami konsep matematika. Hal ini sesuai dengan pendapat (Murniasih \& Ferdiani, 2018) yang mengatakan penggunaan media dapat meningkatkan pemahaman konsep siswa terkait materi tertentu. Berdasarkan hasil dan pembahasan maka perlu dilakukan kegiatan lanjutan pelatihan penggunaan buku saku di SMP untuk materi yang lain. Selain itu perlu adanya pendampingan pada guru dalam membuat buku saku untuk materi yang lain sehingga dapat diajarkan pada siswanya. Adapun dokumentasi kegiatan pengabdian dapat dilihat pada gamber berikut.

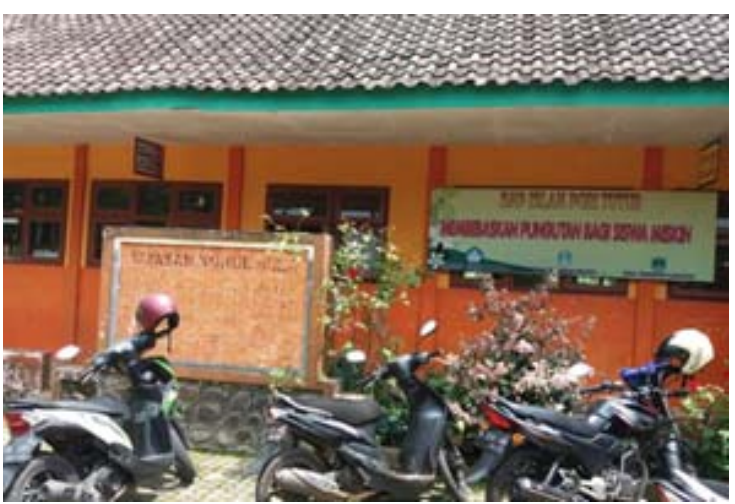

Gambar 2. Kondisi Sekolah SMP Islam PGRI Tutur 


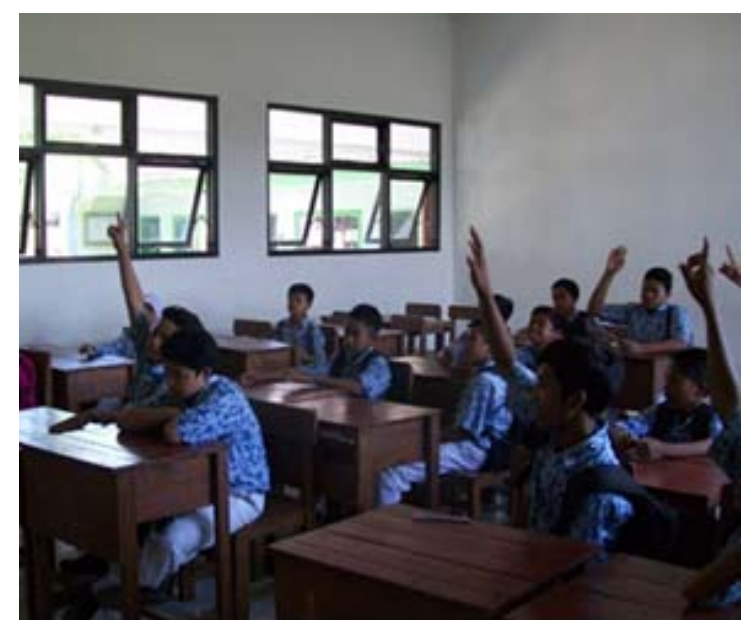

Gambar 3. Siswa Banyak yang Mengangkat Tangan Ketika Pengabdi Menanyakan Minat terkait Penggunaan Media Buku Saku

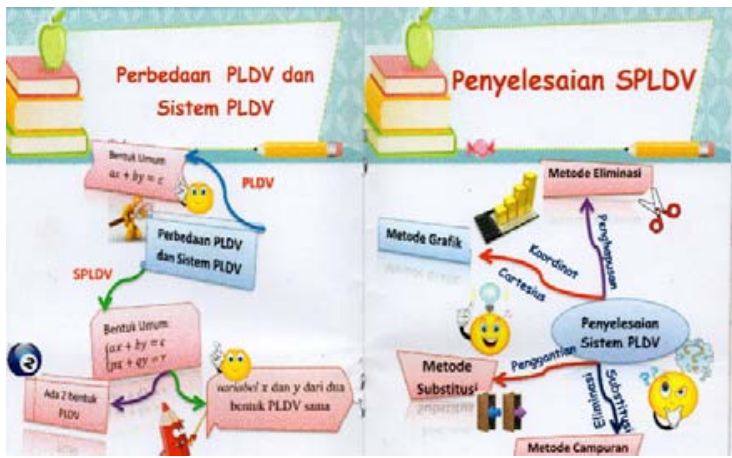

Gambar 4. Contoh Tampilan Media Buku Saku berukuran $10 \times 15 \mathrm{~cm}$ jika Dibuka

\section{SIMPULAN DAN SARAN}

Kegiatan pelatihan penggunaan buku saku pada pengabdian dapat membangun minat siswa SMP khususnya dalam mempelajari materi Sistem Persamaan Linier Dua Variabel. Pengabdian sebaiknya dilaksanakan secara berkelanjutan untuk lebih membangun minat belajar siswa SMP terhadap matematika.

\section{DAFTAR RUJUKAN}

Asyhari, A., \& Silvia, H. (2016). Pengembangan Media Pembelajaran Berupa Buletin dalam Bentuk Buku Saku untuk Pembelajran IPA Terpadu. Jurnal IImiah Pendidikan Fisika Al-Biruni, 5(1), 1.

Ferdiani, R. D., Murniasih, T. R., \& Suwanti, V. (2017). Penggunaan Media Bola - Bola Statistik Untuk. JPM (Jurnal Pemberdayaan Masyarakat), 2(2).

Murniasih, T. R., \& Ferdiani, R. D. (2018). Aksiologiya: Jurnal Pengabdian Kepada Masyarakat Pelatihan Smart
Digram Venn Pada Materi Himpunan SMP, 2(2), 125-130.

Nurkholis. (2013). PENDIDIKAN DALAM UPAYA MEMAJUKAN TEKNOLOGI Oleh: Nurkholis Doktor Ilmu Pendidikan, Alumnus Universitas Negeri Jakarta Dosen Luar Biasa Jurusan Tarbiyah STAIN Purwokerto. Jurnal Kependidikan, 1(1), 24-44.

Sukaesih, S., \& Alimah, S. (2012). Penerapan Praktek Pembelajaran Bermakna Berbasis Better Teaching Learning (BTL) Pada Mata Kuliah Microteaching Untuk Mengembangkan Kompetensi Profesional Calon Guru. Jurnal Penelitian Pendidikan Unnes, 29(2), 165-172. 